\title{
CONVECTION IN MINERAL WOOL USED AS INSULATION FOR BUILDINGS
}

\author{
Vytautas Stankevičius ${ }^{1}$, Valdas Paukštys ${ }^{2}$, Raimondas Bliūdžius ${ }^{3}$, Jolanta Šadauskienė ${ }^{4}$, \\ Zenonas Turskis ${ }^{5}$, Rolandas Samajauskas ${ }^{6}$ \\ 1,2,3,4 Building Physics Laboratory, Institute of Architecture and Construction of Kaunas University of \\ Technology, Tunelio g. 60, LT-3035, Kaunas, Lithuania \\ ${ }^{5}$ Faculcy of Civil Engineering, Vilnius Gediminas Technical University, Sauletekio al. 11, \\ LT-10223 Vilnius, Lithuania \\ ${ }^{6} I E$ “PSB”, Europos av. 121, LT-46339, Kaunas, Lithuania \\ E-mails: 11v.stankevicius@ktu.lt; ${ }^{2}$ valdas.paukstys@ktu.lt (correspondingauthor); ${ }^{3}$ silfiz@asi.lt; \\ ${ }^{4}$ jolanta.sadauskiene@ktu.lt; ${ }^{5}$ zenonas.turskis@vgtu.lt; ${ }^{6}$ infi@psb.lt
}

Received 26 Nov. 2012; accepted 15 Jan. 2013

\begin{abstract}
The paper considers the velocities of air movement in the ventilated air gaps of walls and focuses on pressure fields in both wall models arranged in a climatic chamber and exploited houses. The article investigates the influence of air movement on heat transfer through walls applying numerical modelling methods and conducting experiments in the climatic chamber. The thermal effects of air flows have been described with reference to the Nusselt number defined as the ratio of average convective and conductive heat fluxes and heat flux through still air Keywords: building walls, thermal conductivity, air permeability, air gap.

Reference to this paper should be made as follows: Stankevičius, V.; Paukštys, V.; Bliūdžius, R.; Šadauskienė, J.; Turskis, Z.; Samajauskas, R. 2013. Convection in mineral wool used as insulation for buildings, Journal of Civil Engineering and Management 19(2): 296-304.
\end{abstract}

\section{Introduction}

The building sector consumes about $40 \%$ of the total energy consumed in the European Union. Therefore, the directive issued by the European Parliament and Council (Directive 2010/31/ES) introduces requirements for low energy buildings and modernization of the existing ones. In order to achieve this goal, heat loss from the building sector has to be reduced by increasing the thermal resistance of enclosures. However, with an increment in the thickness of a thermal insulation layer of enclosures, convective heat transfer is formed in the air permeable insulation material due to difference in temperature and wind pressure through it.

Convective heat transfer does not occur in airtight insulating materials, but can take place in air gaps located in the materials wider than $5 \mathrm{~mm}$ (Šadauskienè et al. 2009). According to Roots (1997), convection occurs exclusively in unqualitatively arranged walls, i.e. those having big air cavity. Because of convection, general heat transfer may increase up to $12-13 \%$. As the scholar maintains, small cavities and air gaps have no significant influence on the heat transfer coefficient in walls. However, in the scientific accounts provided by the Centre of Technical Research (VTT) in Finland, contradictory data are presented. Kokko et al. (1997) claim that when mounting thermal-insulating materials, especially solid slabs of mineral wool, the absolute avoidance of small air gaps is impossible. Therefore, the value of the heat transfer coefficient in the thermal-insulating layer may increase up to $20-25 \%$ (Ojanen 1993).

Scientific research on the effect of convection on heat transfer through enclosures has been recently carried out in different countries (Abid 2012; Kokko et al. 1997; Ridouane et al. 2004; Cherif et al. 2009; Tiwari et al. 2012; Ojanen, Kohonen 1995). The obtained results of these studies allows forecasting external conditions for starting air movement and an impact of it on the thermal characteristics of the enclosure. The other scope of the conducted investigation focuses on heat exchange between the outdoor air and the surface of enclosures and as well as on natural convection in air space and fibrous thermal-insulating materials, i.e. mineral wool that fills the entire volume of the enclosure (Nield, Bejan 2006; Lakompte 1990). In addition, many cases of the thermal insulating layer placed between two isothermal and airtight surfaces 
have been also given attention (Bankvall 1992; Kohonen, Ojanen 1989; Samajauskas et al. 2003). Unfortunately, such conditions in many cases are not fulfilled in real constructions of buildings. Thus, in reality, the negative effect of natural and forced convection on the thermal properties of building enclosures has to be much larger, and therefore it has to be thoroughly researched (Abid 2012; Kohonen, Ojanen 1989).

The majority of authors carried out experimental research on the fibrous thermal-insulating materials of a homogeneous structure. The achieved results were amended employing the criteria of similarity between heat transfer and hydrodynamic processes such as Nusselt, Rayleigh, etc. (Altaç, Kurtul 2007; Liu et al. 2011; Alam et al. 2012). However, only concluding these works is not enough, because it underestimates the factors having an influence on the thermal properties of thermal insulating materials.

In real constructions, it is rather difficult to avoid the formation of air gaps having various widths, the movement of air flows caused by wind pressure, differences in temperature as well as the continuity of the wind protecting layer. Hence, it has been decided to analyse the laws on convection taking place in real building constructions by estimating properties of thermal-insulating and wind protecting materials, including environmental factors caused by the climate of Lithuania, i.e. the influence of wind speed, its direction and differences in temperature on air movement in the ventilated air gaps of building enclosures.

\section{Investigation methods}

\subsection{Investigation into walls insulated with air impermeable thermal insulating slabs having small air gaps}

To determine the influence of convection on heat transfer through walls insulated with air impermeable thermal-insulating slabs having small air gaps, computer simulation and experimental investigation into the constructed wall model were carried out.

\subsubsection{Numerical simulation of heat transfer by convection}

PC-programs - AHCond and ANHond - invented by C. E. Hagentoft (1993) were used for the numerical modelling of convection. The introduced programs are used for estimating heat transfer in walls where heat is transmitted by the air moving in small gaps and for establishing the place where at the same time it expands by conduction through air impermeable layers of thermal-insulating materials. The programs employ a two-dimensional model based on the view that both environmental temperature and pressure are stable and the air moves due to difference in wind pressure and temperature.
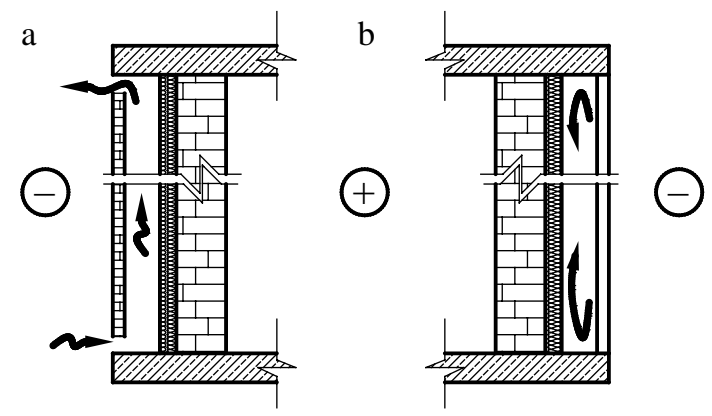

Fig. 1. Schemes for walls having small air gaps used for numerical modelling: a - ventilated small air gap (open); b non-ventilated small air gap (closed)

The influence of convection on stationary heat transmission through the wall having small ventilated and non-ventilated air gaps was calculated using the above mentioned software (Fig. 1). The made calculations used the heat conductivity coefficient of the thermal-insulating layer is $\lambda=0.036 \mathrm{~W} /(\mathrm{m} \cdot \mathrm{K})$, thickness $d=0.15 \mathrm{~m}$, height $h=2.2 \mathrm{~m}$ and the thickness of a small air gap $b=3 ; 5 ; 10$ and $15 \mathrm{~mm}$. The calculation results, regarding the effect of convection in all cases indicated in Table 1, are presented in Fig. 2.

The achieved results have disclosed that the effect of natural convection on heat transfer through the thermal-insulating layer mostly depends on the thickness of a small air gap and difference in temperature but rather insignificantly on the tightness of the gap. In case of forced convection, the formation of any small gap increases general heat transfer through the wall from two to thirteen times. Therefore, heat transfer in the case of forced convection was not further investigated. However, the dependence of heat transfer through the construction on the thickness of the air gap and difference in temperature was specified. The results are presented in Fig. 3.

The analysis of the results of numerical modelling (Fig. 3) shows that the influence of natural convection on general heat transfer is insignificant when a joining small air gap up to $3.0 \mathrm{~mm}$ thickness occurs around the thermal-insulating layer. In larger $(b>3.0 \mathrm{~mm})$ air gaps, the effect of natural convection on general heat transfer increases. It may be explained by the interruption of natural air movement in narrow air gaps caused by hydraulic friction. The data given in Fig. 3 demonstrate difference in the significant $35 \%$

Table 1. Data for modelling the influence of convection on heat transmission

\begin{tabular}{|c|c|c|}
\hline Air gap & Closed & Open \\
\hline Convection & Natural & $\begin{array}{ll}\text { Natural } & \begin{array}{l}\text { Natural and forced } \\
(\operatorname{grad} P=3 \mathrm{~Pa} / \mathrm{m})\end{array}\end{array}$ \\
\hline $\begin{array}{l}\text { Thickness } b, \mathrm{~mm} \\
\Delta \theta,{ }^{\circ} \mathrm{C}\end{array}$ & & $\begin{array}{l}3 ; 5 ; 10 ; 15 \\
10 ; 20 ; 30 ; 40\end{array}$ \\
\hline
\end{tabular}




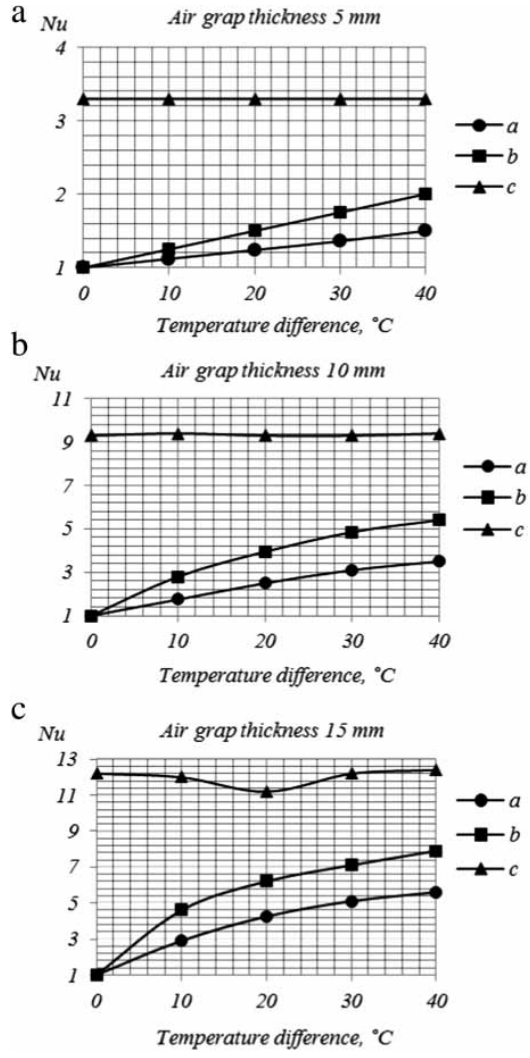

Fig. 2. The dependence of convection on difference in temperature, the thickness of the air gap and its tightness: $\mathrm{a}$ - small air gap is closed (natural convection); $\mathrm{b}$ - small air gap is open (natural convection); c - small air gap is open (forced convection)

$N u$ criterion value in the cases of non-ventilated and ventilated constructions.

As mentioned above, the performed investigation determined rather frequent cases when air gaps and cavities occurred between thermal-insulating products mounted in the wall constructions of the building as well as between those products and their limiting surfaces in the exploited buildings.

The places of the above mentioned gaps in walls depend on numerous factors: the properties of the wall material, mounting technology, etc. Since, because of convection, heat transfer through the wall with small air gaps is markedly greater than heat transfer through monolithic walls, it must be estimated in the calculations of thermal resistance and heat transfer coefficients. Furthermore, several calculation results regarding the thermal properties of the thermal-insulating layer with small air gaps $(\lambda=0.036 \mathrm{~W} /(\mathrm{m} \cdot \mathrm{K}) ; d=0.15 \mathrm{~m}$; $h=2.2 \mathrm{~m} ; b=5.0 \mathrm{~mm}$ ) in various places of walls (Fig. 4) are presented in Fig. 5.

The achieved functional dependence of the values of Nusselt criterion on difference in temperature is presented in Fig. 5. The figure shows that, when the small air gap is on the cold part of thermal insulation, the effect of natural convection is insignificant.

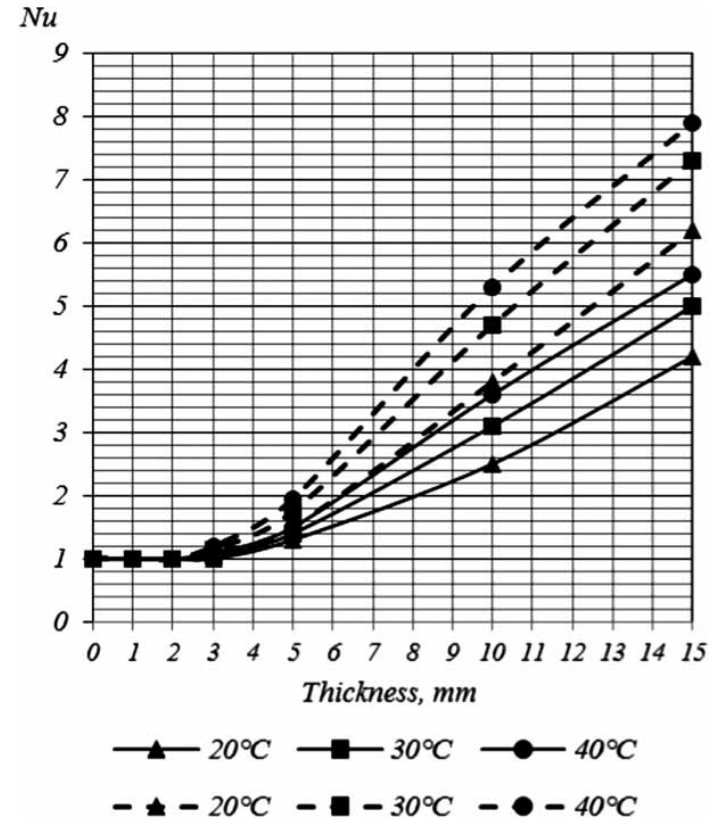

Fig. 3. The dependence of the $\mathrm{Nu}$ criterion of construction with impermeable thermal-insulating slabs on the thickness of small air gaps and difference in temperature: - nonventilated small air gap; ---- ventilated small air gap

However, heat transfer through the construction increases markedly when the air gap is situated between thermal insulation and the warm side of the construction as well as when the construction is ventilated. Because of convection, heat transmission through the above mentioned construction increases 1.5 times when difference in temperature is $20^{\circ} \mathrm{C}$, and 2 times when it reaches $40{ }^{\circ} \mathrm{C}$.

\subsubsection{Investigation into walls insulated with air permeable thermal insulating slabs}

Experimental analysis was carried out in order to determine the reliability of numerical modelling. Theoretically calculated values of the Nusselt criterion

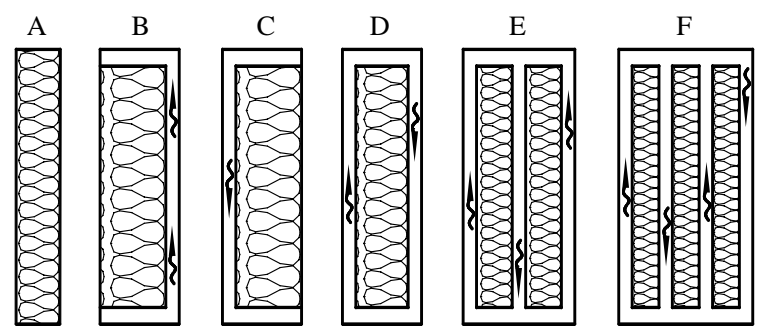

Fig. 4. The places showing the location of the air gap in constructions. The left side of the construction is warm, the right side is cold: A - thermal-insulation without air gaps; B small air gap in the cold side of thermal-insulation; C separate small air gap on the warm side of thermal-insulation; $\mathrm{D}$ - connecting small air gaps on the warm and cold sides; $\mathrm{E}$ two layers of slabs and three small air gaps; F - three layers of slabs and four small air gaps 


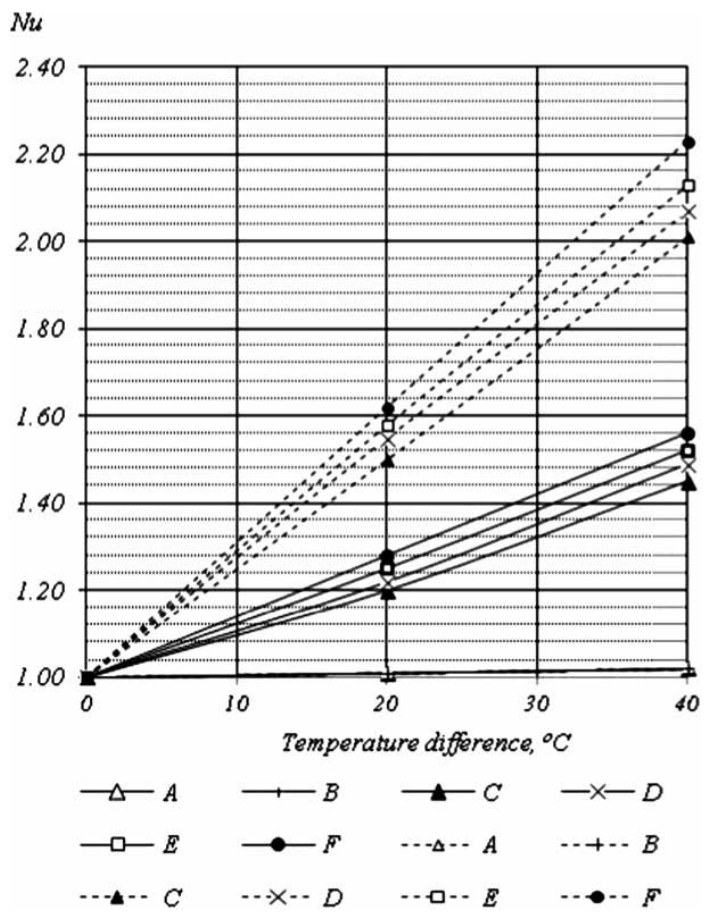

Fig. 5. The dependence of the $\mathrm{Nu}$ criterion in: - nonventilated and ---- ventilated constructions on difference in temperature when small air gaps are of $5 \mathrm{~mm}$ thickness

of constructions with natural convection in the small air gaps of the wall were compared with the results of experimental analysis. Special equipment was created for experimental analysis according to the requirements of international standards ISO 8301 and ISO 8990. The height of constructions tested in this equipment was $2100 \mathrm{~mm}$, width $-1100 \mathrm{~mm}$ and thickness $-150 \mathrm{~mm}$. The values of temperature and heat flow density in the sample were measured under stationary environmental conditions when the indoor temperature in equipment was $\theta_{i}=+20{ }^{\circ} \mathrm{C}$, and the temperature of climatic chamber $\theta_{e}=0{ }^{\circ} \mathrm{C}$ and $\theta_{e}=-10{ }^{\circ} \mathrm{C}$. The measurement was carried out both in the horizontal position of equipment with closed ventilated orifices (basic measuring) and in the vertical position with closed and opened ventilation orifices. The total area of fully opened ventilated orifices in bottom and top parts covered $15000 \mathrm{~mm}^{2} / \mathrm{m}$. For experimental analysis, the thermal conductivity of polystyrene foam slabs of $50 \mathrm{~mm}$ thickness was $0.036 \mathrm{~W} /(\mathrm{m} \cdot \mathrm{K})$. It should be emphasized that polystyrene foam slabs are, in fact, air impermeable, and therefore the influence of small air gaps between slabs and other layers determined that small air gaps up to $5 \mathrm{~mm}$ thickness were formed between slabs that appeared practically impossible to be avoided during mounting. That is why the wall model having $5 \mathrm{~mm}$ air gaps between thermal-insulating slabs had been chosen. Fig. 6 presents a scheme of the construction mounted in equipment (3 layers of slabs and 4 small air gaps).

Considering all types of measuring both cold and warm sides of equipment, the vertical temperature gradient of approximately $0.1-0.2{ }^{\circ} \mathrm{C} / \mathrm{m}$ was formed. Thus, the temperatures of external surfaces were different throughout the whole height. When calculating the Nusselt criterion values of the whole construction, the unevenness of the above mentioned temperature found in the places of heat flow density measurement was estimated by the equation:

$$
\mathbf{N u}=\frac{\sum_{i=1}^{n} \frac{q_{c v, i}}{\Delta \theta_{c v, i}}}{\sum_{i=1}^{n} \frac{q_{c d, i}}{\Delta \theta_{c d, i}}},
$$

where: $n$ - the number of heat flow density measuring sensors; $q_{c v}-$ density of heat flow rate transmitted by convection, $\mathrm{W} / \mathrm{m}^{2} ; q_{c d}-$ density of heat flow transmitted by conductivity, $\mathrm{W} / \mathrm{m}^{2}$.

Fig. 7 presents air temperature in the gaps where the construction is vertical, ventilation orifices are closed and the construction is not ventilated.

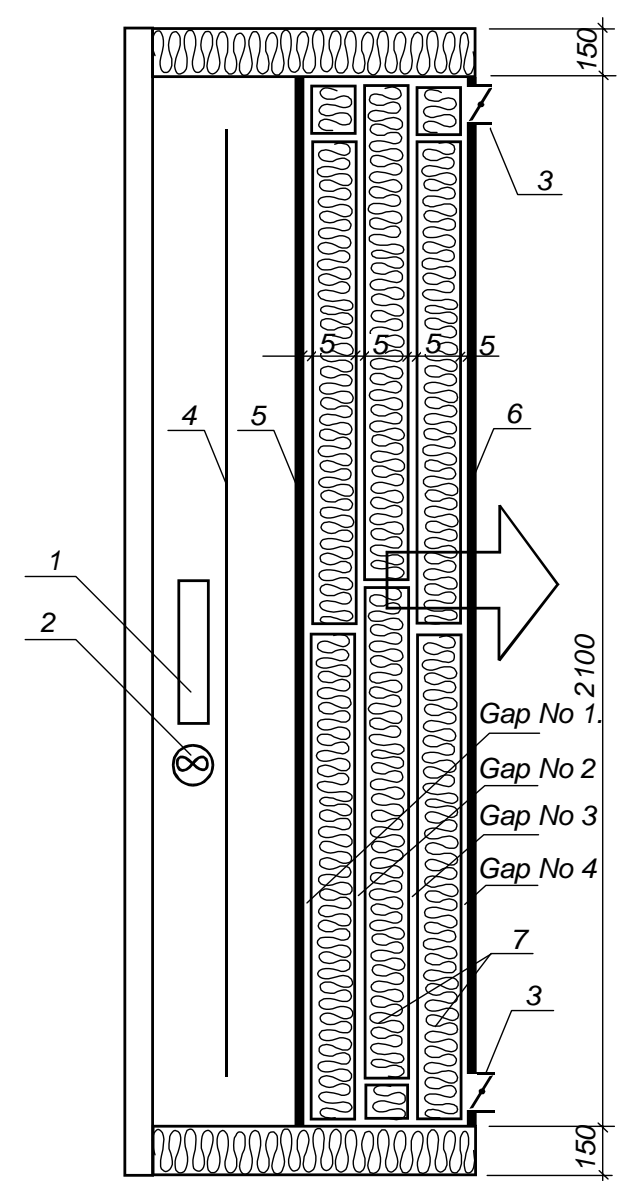

Fig. 6. The scheme of equipment, including a sample: 1 heater; 2 - ventilator; 3 - ventilation orifices; 4 - protection from radiation; 5 - warm slab; 6 - cold slab with measuring sensors of heat flow density ( 8 units); 7 - polystyrene foam slabs 

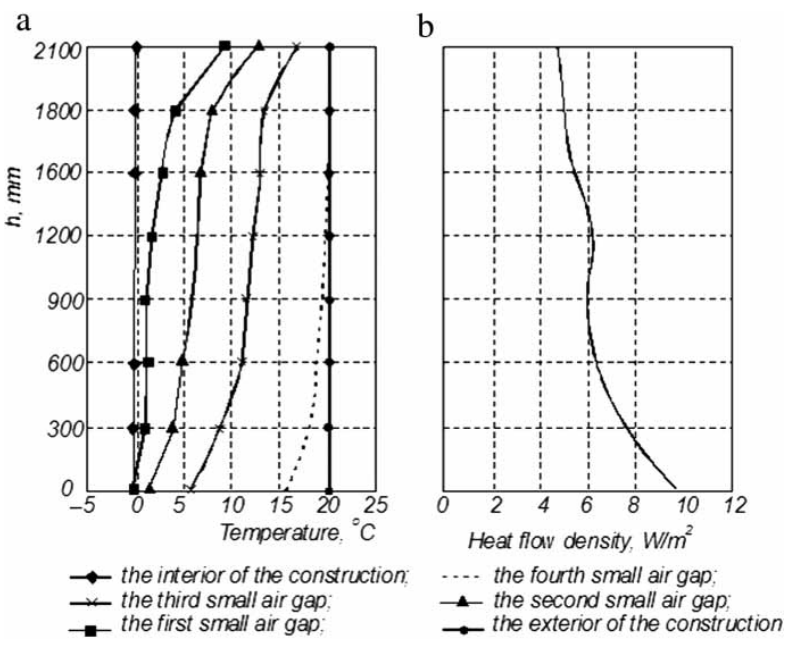

Fig. 7. Air temperatures (a) and heat flow density (b) in the gaps of the non-ventilated (closed) construction. The sample in the vertical position when $\theta_{i}=+20^{\circ} \mathrm{C}, \theta_{e}=0{ }^{\circ} \mathrm{C}, \Delta \theta=20^{\circ} \mathrm{C}$

Natural convection in the climatic chamber started at the temperature of $\theta_{e}=0{ }^{\circ} \mathrm{C}$, and therefore temperature curves were distorted in comparison with the basic measurement. Temperature in the top part of the air gaps of the construction increased by $3 \div 5{ }^{\circ} \mathrm{C}$ and in the bottom part decreased by $3 \div 5^{\circ} \mathrm{C}$. Temperature in the construction where height varied from $0.6 \mathrm{~m}$ to $1.4 \mathrm{~m}$ remained unchanged.

When ventilation orifices were opened,, external air entered the construction through its lower part and went out through its upper part because of natural convection. In this case, temperature in the air gaps of the lower part of the construction decreased by approximately $10{ }^{\circ} \mathrm{C}$, whereas in the upper part it remained unchanged as it was in the closed construction.

Other experiments on the ventilated construction at difference in temperature $30{ }^{\circ} \mathrm{C}$ (Fig. 8) were also carried out. When ventilated orifices were opened ( $\left.A=15000 \mathrm{~mm}^{2} / \mathrm{m}\right)$, different results were achieved: the temperature of the air gap closest to the warm surface decreased up to $+12{ }^{\circ} \mathrm{C}$ and the temperature of other air gaps in the lower part of the construction decreased below $0{ }^{\circ} \mathrm{C}$.
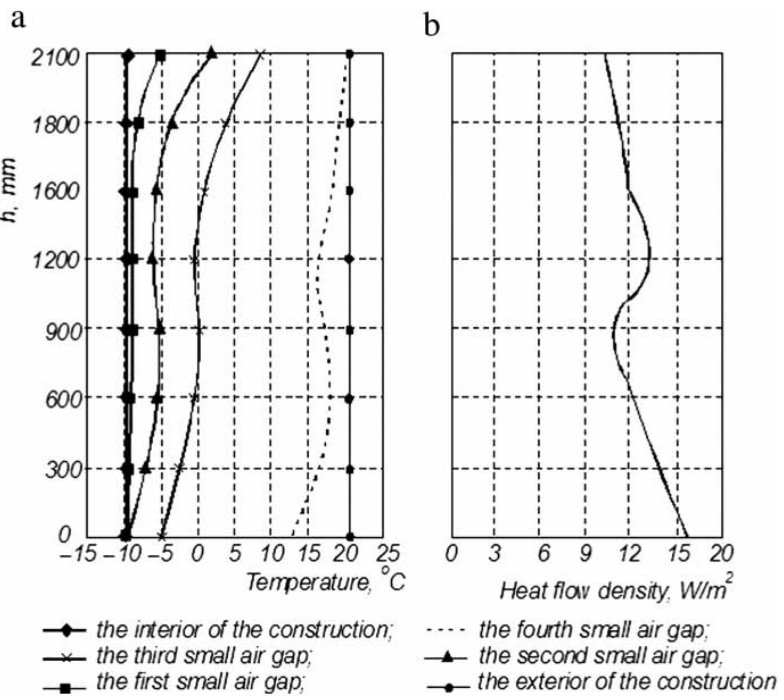

Fig. 8. Air temperatures (a) and heat flow density (b) of the gaps in the ventilated construction. The sample in the vertical position when $\theta_{i}=+20{ }^{\circ} \mathrm{C}, \theta_{e}=-10{ }^{\circ} \mathrm{C}$ and $\Delta \theta=30{ }^{\circ} \mathrm{C}$

Both numerical modelling and experimental results revealed that along with changes in the thickness of the non-ventilated air gap from 0 to 15 $\mathrm{mm}$, heat transfer through the construction increased up to 8 times. A nearly analogous situation can be observed with regard to the change of thermal resistance under the ventilated air gap. In the opposite case, when the air in the wall cannot "wash" the thermal-insulating layer, i.e. air gaps that are both in the cold and warm sides of thermal insulation do not join, total convective heat transfer will not increase.

\subsection{Investigation into the effect of convection on heat transfer through building walls insulated with air permeable thermal-insulating slabs}

The further development of the paper analyses the effect of natural and forced convections on general heat transfer through ventilated building walls and junctions of walls (wall - wall and wall - attic) thermally insulated with air permeable mineral wool. The thermal-technical properties of these materials are presented in Table 2.

Table 2. Thermal-technical properties of thermal-insulating materials

\begin{tabular}{llcccc}
\hline & & & \multicolumn{2}{c}{$\begin{array}{c}\text { Thermal conductivity } \\
\lambda_{10}, \mathrm{~W} /(\mathrm{m} \cdot \mathrm{K})\end{array}$} & Air permeability $l, \mathrm{~m}^{3} /(\mathrm{m} \cdot \mathrm{s} \cdot \mathrm{Pa})$ \\
\cline { 3 - 4 } Mineral wool & Mark & Density $\rho, \mathrm{kg} / \mathrm{m}^{3}$ & $\lambda_{\perp}$ & $\lambda_{/ l}$ & $251.0 \cdot 10^{-6}$ \\
\hline Rock wool & MV-4 & 22.3 & 0.0375 & 0.0430 & $152.0 \cdot 10^{-6}$ \\
Glass wool & MV-5 & 19.2 & 0.0358 & 0.0379 & $125.0 \cdot 10^{-6}$ \\
Rock wool & MV-6 & 32.7 & 0.0345 & 0.0380 & $110.0 \cdot 10^{-6}$ \\
Rock wool & MV-7 & 38.1 & 0.0344 & 0.0378 & $70.9 \cdot 10^{-6}$ \\
Rock wool & MV-8 & 57.6 & 0.0337 & 0.0376 & \\
\hline
\end{tabular}


Table 3. Thermal-technical properties of wind protecting products

\begin{tabular}{lcccc}
\hline Product & Mark & $d, \mathrm{~mm}$ & Air permeance $K, \mathrm{~m}^{3} /\left(\mathrm{m}^{2} \cdot \mathrm{s} \cdot \mathrm{Pa}\right)$ & Thermal resistance $R,\left(\mathrm{~m}{ }^{2} \cdot \mathrm{K}\right) / \mathrm{W}$ \\
\hline Glass fibre & VI-1 & 0.6 & $17024 \cdot 10^{-6}$ & - \\
LDPE $* *$ & VI-2 & 0.2 & - & - \\
HDPE $*$ & VI-3 & 0.15 & $2.45 \cdot 10^{-6}$ & - \\
Wood fibre board & VI-4 & 12.0 & $23.2 \cdot 10^{-6}$ & 0.075 \\
Glass wool board & VI-5 & 13.0 & $46.4 \cdot 10^{-6}$ & 0.406 \\
Rock wool board & VI-6 & 30.0 & $633 \cdot 10^{-6}$ & 0.938 \\
Rock wool board & VI-7 & 30.0 & $1126 \cdot 10^{-6}$ & 0.882 \\
\hline
\end{tabular}

* Water vapour permeable polyethylene pellicle of light density;

** The low density of the polyethylene pellicle impermeable to air and water vapour. This product cannot be used for protecting mineral wool layers against the impact of the wind. However, it was included in the experiment as a rolling product absolutely non-conductive to the air.

Table 2 presents the values of the resultant air permeability of mineral wool. These values are expressed by the following formula:

$$
l_{r e}=\frac{4 \cdot l_{\perp} \cdot l_{I I}}{\left(\sqrt{l_{\perp}}+\sqrt{l_{I I}}\right)^{2}}
$$

where: $l_{\perp}, l_{I I}$ - air permeability of the porous medium, perpendicular and parallel to heat transfer direction, $\mathrm{m}^{2}$.

Different materials were used as wind protecting layers the air permeability and thermal resistance of which are presented in Table 3. For conducting experiments, sheet materials were preferred, since they were stiff and attached close to the thermalinsulating layer.

At the first stage of experimentation, when modelling heat transfer regarding conductivity only, the values of heat flow density in the construction as well as the temperatures of layers were calculated with the help of numerical modelling software DAVID-32 (Table 4).

Calculations were made considering 34 thermalinsulating and wind protecting layer combinations. The received values were used as the initial data when calculating the values of the $N u$ criterion, i.e. an increase in heat transfer because of the effect of convection and air filtration.

Further, the values of wall heat flow density as well as the temperatures of the layers were measured at natural and forced convection. Ventilation orifices covering the area of $A=40000 \mathrm{~mm}^{2} / \mathrm{m}$ were opened both in the upper and lower parts of each wall fragment. At this stage, the air in the wall moved only because of natural convection. Later, applying a ventilator, the air pressure gradient of $3.0 \mathrm{~Pa} / \mathrm{m}$ was formed in the air gap.

Fig. 9 presents the most typical temperature and heat flow density curves found when analysing a sample of non-wind-protected stone wool $(p=22.3$ $\mathrm{kg} / \mathrm{m}^{3}$ ) in both natural and forced convection.

The values of the Nusselt criterion were determined following experiments on various thermalinsulating and wind protecting combinations. The summary results of the made calculations are presented in Figs 10 and 11.

The test results (Fig. 10) show that, because of natural convection, when mineral wool thermal-insulating layers are not protected against wind, heat transfer through the walls may increase up to $15 \%$.

Table 4. The calculated average heat flow density values of the non-ventilated wall under air temperatures $\theta_{e}=-10.0{ }^{\circ} \mathrm{C}$, $\theta_{1}=+22.0{ }^{\circ} \mathrm{C}$ and $\Delta \theta=32.0{ }^{\circ} \mathrm{C}$

\begin{tabular}{lcccccc}
\hline & & \multicolumn{3}{c}{$\begin{array}{c}\text { Calculated average heat flow density values } q, \mathrm{~W} / \mathrm{m}^{2}, \text { when a cold surface of mineral } \\
\text { wool is covered with wind protection product: }\end{array}$} \\
\cline { 3 - 6 } Sample & $d, \mathrm{~mm}$ & VI-1; VI-2; VI-3 & VI-4 & VI-5 & VI-6 & VI-7 \\
\hline MV-4 & 100 & 10.24 & 10.00 & 9.06 & - & - \\
& 150 & 7.18 & 7.06 & 6.58 & - & - \\
MV-5 & 100 & 9.84 & 9.62 & 8.75 & - & - \\
& 150 & 6.88 & 6.78 & 6.33 & - & - \\
MV-6 & 100 & 9.53 & 9.32 & 8.50 & 7.45 & 7.55 \\
& 150 & 6.66 & 6.56 & 6.14 & 5.57 & 5.63 \\
MV-7 & 100 & 9.51 & 9.30 & 8.49 & 7.44 & 7.53 \\
& 150 & 6.64 & 6.54 & 6.12 & 5.56 & 5.61 \\
MV-8 & 100 & 9.34 & 9.14 & 8.35 & - & - \\
& 150 & 6.52 & 6.42 & 6.02 & - & - \\
\hline
\end{tabular}



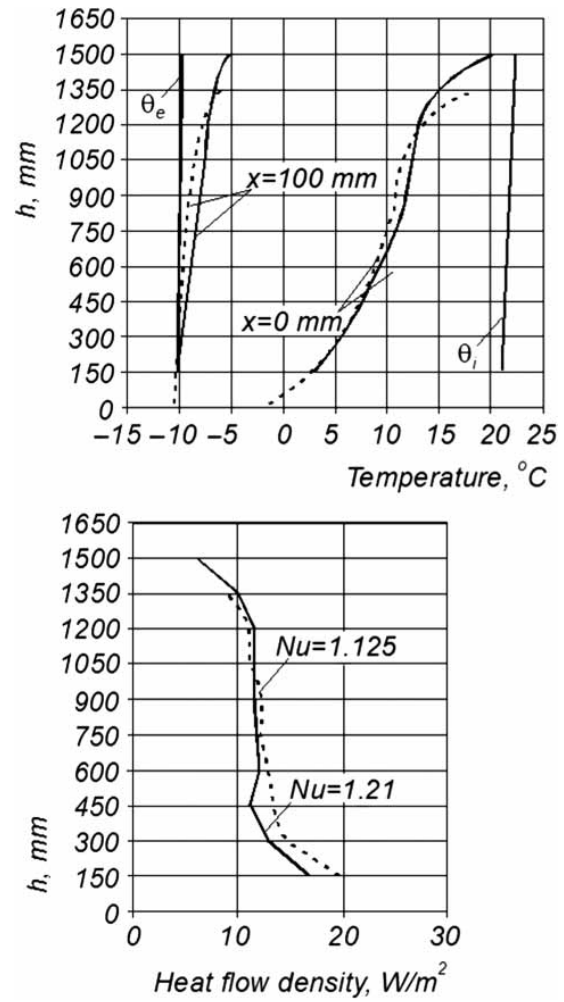

Fig. 9. Temperature curves and heat flow density values in the ventilated construction considering sample MV-4 in cases of natural and forced convection $(\operatorname{grad} P=3.0 \mathrm{~Pa} / \mathrm{m})$ when $\theta_{i}=+20{ }^{\circ} \mathrm{C}, \theta_{e}=-10{ }^{\circ} \mathrm{C}$. The external thermalinsulating layer is non-wind-protected. Straight lines mark the values of the Nusselt criterion when heat transfer is affected only by natural convection; dotted lines mark the effect of both natural and forced convection $(\operatorname{grad} P=$ 3.0 $\mathrm{Pa}$ )

The effect of convection on heat transfer increases under a lower density (also at higher air permeability) of the thermal-insulating material and higher thickness of the thermal-insulating layer. When the air pressure gradient in the wall air gap reached 3.0 $\mathrm{Pa}$, the opposite results were achieved: heat transfer was more intensive in thinner $(100 \mathrm{~mm})$ layers and increased up to $25 \%$. The test results presented in Fig. 10 show that, because of convection, heat transfer increased by approximately $5-7 \%$ when the mineral wool slabs of higher density were used for wall insulation. In the case of materials having low air permeability, convection took place in the air gaps between slabs and between slabs and the wall or carcass elements, which, actually, increased heat transfer. The results achieved during the performed experiments (Fig. 10) indicate that under natural convection, heat transfer through the walls the thermal-insulating layer of which is made of mineral wool slabs $\left(l<70.0 \times 10^{-6} \mathrm{~m}^{3} /(\mathrm{m} \cdot \mathrm{s} \cdot \mathrm{Pa})\right)$ without the windprotecting layer will not be higher than $5-7 \%$. Therefore, in constructions with no forced air movement

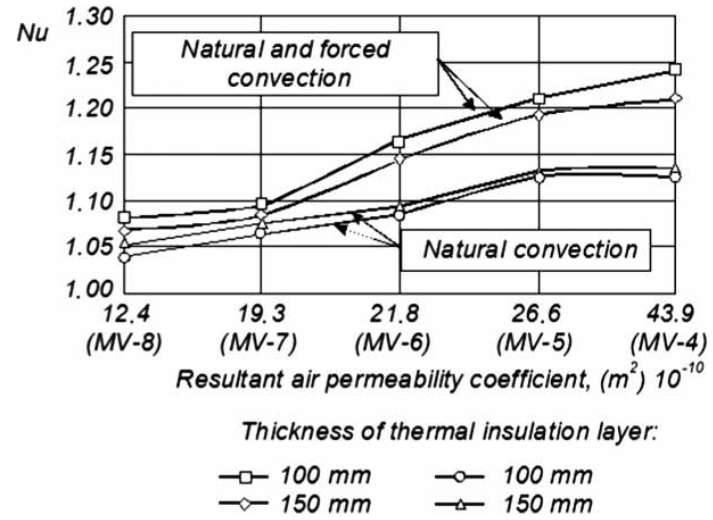

Fig. 10. The dependence of the Nusselt criterion on the resultant air permeability coefficient of mineral wool and the thickness of the layer when the external layer is non-windprotected. The measurement carried out under environmental temperatures $\theta_{i}=+20{ }^{\circ} \mathrm{C}$ and $\theta_{e}=-10{ }^{\circ} \mathrm{C}$

(i.e. when the equivalent orifice area in the ventilated air gap does not exceed $3000 \mathrm{~mm}^{2} / \mathrm{m}$ ), less permeable and denser materials with no wind protecting should be used for thermal-insulating layers.
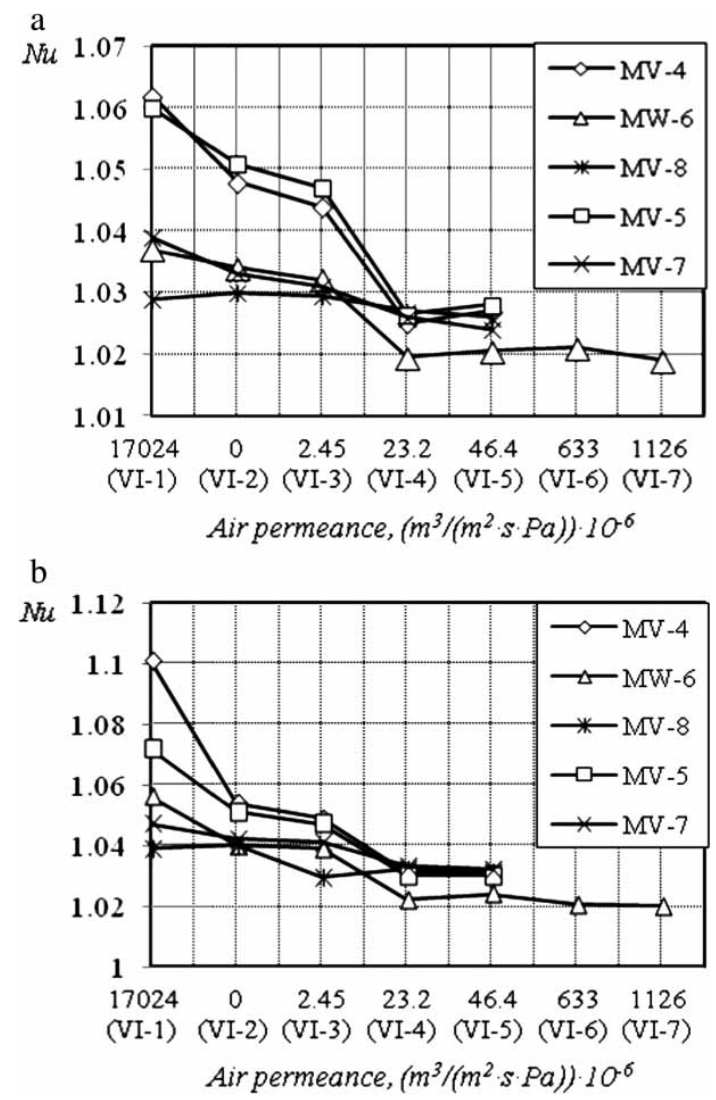

Fig. 11. The dependence of the Nusselt criterion of thermalinsulating layer $(d=150 \mathrm{~mm})$ on the air permeance of wind protection and its type when heat transfer is affected exclusively by natural convection (a) by both natural and forced convection ( $\operatorname{grad} P=3.0 \mathrm{~Pa}$ ) (b). The measurements carried out under environmental temperatures $\theta_{i}=+20{ }^{\circ} \mathrm{C}$ and $\theta_{e}=-10{ }^{\circ} \mathrm{C}$ 
The results of investigation into heat transfer through the walls of various constructional solutions (Fig. 11) show that heat transfer in the walls does not significantly depend on the air permeability of wind protection when the air permeability of sheet wind protection varies from $23.2 \cdot 10^{-6}$ to $1126 \cdot 10^{-6} \mathrm{~m}^{3} /$ $\left(\mathrm{m}^{2} \cdot \mathrm{s} \cdot \mathrm{Pa}\right)$. Heat transfer through walls increases when rolling membrane materials are used for wind protection. These materials unevenly attaches to the layer of the thermal-insulating material, and thus additional air gaps are formed thus increasing the heat transfer through the wall.

\section{Conclusions}

The results of investigation into air pressure put in the air gaps of building walls show big differences in air pressure formed exclusively in the air gaps of intensively ventilated walls (area of ventilated orifices $A>40000 \mathrm{~mm}^{2} / \mathrm{m}$ ). The influence of wind velocity on air movement in the air gaps of enclosures is insignificant when the area of ventilated orifices is smaller than $3000 \mathrm{~mm}^{2} / \mathrm{m}$. The pressure gradient in the ventilated air gaps of small buildings with the area of ventilated orifices from 3000 to $40000 \mathrm{~mm}^{2} / \mathrm{m}$ does not depend on wind speed and makes $2-3 \mathrm{~Pa} / \mathrm{m}$.

The results of numerical modelling show that the influence of natural convection on general heat transfer is insignificant when air gaps around the thermal-insulating layer are up to $3.0 \mathrm{~mm}$ thickness.

The results of investigation into heat transfer through the walls of various constructional solutions disclose that heat transfer in the walls does not significantly depend on the air permeability of wind protective slabs when air permeance varies from 23.2. $10^{-6}$ to $1126 \cdot 10^{-6} \mathrm{~m}^{3} /\left(\mathrm{m}^{2} \cdot \mathrm{s} \cdot \mathrm{Pa}\right)$.

Wind protective slabs to be applied to the mineral wool insulation of intensively ventilated $\left(A>40000 \mathrm{~mm}^{2} / \mathrm{m}\right)$ walls must have the air permeance value lower than $50.0 \cdot 10^{-6} \mathrm{~m}^{3} /\left(\mathrm{m}^{2} \cdot \mathrm{s} \cdot \mathrm{Pa}\right)$. Air impermeable layers should be arranged in thermalinsulating layers in order to stop internal air filtration.

\section{References}

Abid, A. F. 2012. Natural convection heat transfer enhancement in air filled rectangular enclosures with portirions, Al-Qadisiya Journal for Engineering Sciences 5(2): 191-208.

Alam, P.; Kumar, A.; Kapoor, S.; Ansari, S. R. 2012. Numerical investigation of natural convection in a rectangular enclosure due to partial heating and cooling at vertical walls, Communications in Nonlinear Science and Numerical Simulation 17(6): 2403-2414. http://dx.doi.org/10.1016/j.cnsns.2011.09.004

Altaç, Z.; Kurtul, Ö. 2007. Natural convection in tilted rectangular enclosures with a vertically situated hot plate inside, Applied Thermal Engineering 27(11-12):
1832-1840. http://dx.doi.org/10.1016/j.applthermaleng.2007.01.006

Bankvall, C. G. 1992. Thermal insulation and research in heat transfer, in A. Elmorth, L. E. Nevander (Eds.). Research and development in building physics during the last 25 years: symposium to celebrate Professor Lars Erik Nevander's, 70 years birthday, Stockholm: Swedish Council for Building Research, 29-35.

Directive 2010/31/EC of the European Parliament and of the Council of 19 May 2010 on the energy performance of buildings (recast), Brussels [cited 26 June 2012]. Available from Internet: http://eur-lex.europa.eu/ LexUriServ/ LexUriServ.do?uri=OJ:L:2010:153:0013: 0035:EN:PDF.

Cherif, Y.; Joulin, A.; Zalewski, L.; Lassue, S. 2009. Superficial heat transfer by forced convection and radiation in a horizontal channel, International Journal of Thermal Sciences 48(9): 1696-1706.

http://dx.doi.org/10.1016/j.ijthermalsci.2009.01.017

Hagentoft, C. E. 1993. Thermal effects due to air flows in cracks, in Building Physics in the Nordic Countries (Building Physics '93), 13-15 September, 1993, Copenhagen, Denmark, 1: 153-160.

Kohonen, R.; Ojanen, T. 1989. Coupled diffusion and convection heat and mass transfer in building structures, in Research Reports. Technical research centre of Finland, 247-251.

Kokko, E.; Ojanen, T.; Salonvaara, M. 1997. New building envelope structures. Espoo: Research reports No. 1869. Technical research centre of Finland. 90 p.

Lakompte, J. 1990. The influence of natural convection on the thermal quality of insulated cavity construction, Building Research and Practice 6: 345-354.

Liu, D.; Zhao, F.-Y.; Wang, H.-Q. 2011. Passive heat and moisture removal from a natural vented enclosure with a massive wall, Energy 36(5): 2867-2882. http://dx.doi.org/10.1016/j.energy.2011.02.029

Nield, D. A.; Bejan, A. 2006. Convection in porous media. 3rd ed. Berlin: Springer. 640 p.

Ojanen, T.; Kohonen, R. 1995. Hygrothermal performance analysis of wind barrier structures, in ASHRAE/DOE/ BTECC Conference on Thermal Performance of the Exterior Envelopes of Buildings IV, 4-7 December, 1989, Orlando, Florida, 234-249.

Ojanen, T. 1993. Criteria for hygrothermal performance of wind barriers structures, in Building Physics in the Nordic Countries (Building Physics'93), 13-15 September, 1993, Copenhagen, Denmark, 2: 643-652.

Ridouane, E. H.; Hasnaoui, M.; Amahmid, A.; Raji, A. 2004. Interaction between natural convection and surface radiation in a square cavity heated from below, Numerical Heat Transfer, Part A: Applications: An International Journal of Computation and Methodology 45(3): 289-311.

Roots, P. 1997. Heat transfer though a well insulated external wooden frame wall. $\mathrm{PhD}$ thesis. Lund University, Lund, Sweden. 173 p.

Samajauskas, R.; Stankevičius, V.; Bliūdžius, R. 2003. The effect of convection on heat transfer through the ventilated building partitions. Monograph. Kaunas: Technologija. $166 \mathrm{p}$. 
Šadauskienè, J.; Buska, A.; Burlingis, A.; Bliūdžius, R.; Gailius, A. 2009. The effect of vertical air gaps to thermal transmittance of horizontal thermal insulating layer, Journal of Civil Engineering and Management 15(3): 309-315.

http://dx.doi.org/10.3846/1392-3730.2009.15.309-315
Tiwari, A. K.; Singh, A. K.; Chandran, P.; Sacheti, N. C. 2012. Natural convection in a cavity with a sloping upper surface filled with an anisotropic porous material, Acta Mechanica 223(1): 95-108. http://dx.doi.org/10.1007/s00707-011-0544-5

Vytautas STANKEVIČIUS. Prof. Dr Habil, the author of more than 230 papers and 4 patents. Research interests: physical properties of building materials, physical-technical processes in building envelopes, energy saving in buildings, weather durability of the external finish of building walls.

Valdas PAUKŠTYS. Assoc. Prof. Dr, researcher at the Laboratory of Thermal Building Physics at the Institute of Architecture and Construction, Kaunas University of Technology (KTU). Research interests: the moisture state of building constructions, physical-technical processes in building envelopes, heat loss in buildings.

Raimondas BLIŪDŽIUS. Prof. Dr, chief researcher at the Laboratory of Thermal Building Physics at the Institute of Architecture and Construction, KTU. Research interests: heat transfer, technical properties of thermal insulations products.

Jolanta ŠADAUSKIENĖ. Assoc. Prof. Dr, researcher at the Laboratory of Thermal Building Physics at the Institute of Architecture and Construction, KTU. Research interests: the moisture state of building constructions, physicaltechnical processes in building envelopes, heat loss in buildings.

Zenonas TURSKIS. Prof. Dr of Technical Sciences, a senior research fellow at the Laboratory of Construction Technology and Management, Vilnius Gediminas Technical University. Research interests: building technology and management, decision-making theory, computer-aided automation in design, expert systems.

Rolandas SAMAJAUSKAS. Dr of Technical Sciences, Expert, IE 'PSB'. Research interests: heat transfer, technical properties of thermal insulations products. 